\title{
A NOVEL SSR-COUNTERMEASURE THROUGH APPROPRIATE DESIGN OF THE SHAFT- DYNAMIC PARAMETERS
}

\author{
A. S. Abdel-Ghaffar* A. H. Morsi* A. M. Abdel-Hamid* M. A. Elmashad** \\ * Department of Electrical Engineering, Faculty of Engineering, El-Minufiya University, \\ Shebin El-kom, Egypt. \\ ** Senior Engineer of Advanced Power Application, NECC, Egypt.
}

\begin{abstract}
This paper presents a novel trend toward retirement of the strong oscillations which may exist if the power system is exposed to Subsynchronous Resonance. (SSR) phenomenon. Since these harmful oscillations are mainly due to the oscillatory modes of the turbo-generator shaft, the idea of this trend is to suggest an appropriate design of the shaft-parameters such that the SSR phenomenon may be fundamentally avoided. The effect of shaft parameters like the spring constant and the inertia constant on the shape and location of these oscillatory modes is extensively studied. Modal analysis, eigenvalue analysis, and nonlinear time simulation are used as tools to design a turbo-generator shaft which achieve minimum oscillations. Practical constraints are taken in consideration in a way that the proposed design can be agreeably manufactured.
\end{abstract}

Keywords: SSR, Excitation System, IEEE-SSR Benchmark model, Oscillatory modes, mode shapes, Eigenvalues, SSR countermeasures, Torsional oscillations.

\section{INTRODUCTION}

In 1970 and 1971, two shaft failures at Mohave power station (United State of America) have occurred [1,2]. Extensive studies and tests are established trying to find out the reasons of such failures. Analysis reports showed that SSR was the reason of this problem. SSR is an electric power system condition where the electric network exchange energy with a turbine generator at one or more of the natural frequencies of the combined system below the synchronous frequency of the system [3]. In the last two decades, the Egyptian Power Network (EPN) has been grown and different stations have been installed with units haying nearly the same ratings as used worldwide. Such accidents which has happened in Mohave were about to exist in the units of Shoubra El-kheima power station. However, this network has exposed to SSR problem during the month of November, $1992,12^{\text {th }}$, and $18^{\text {th }}$, at its $220 \mathrm{kv}$ network because of the extremely bad weather conditions at that time [4].

Manuscript received from Dr. A. M. Abdel-Hamid on : 24/5/2000

Accepted on : $7 / 6 / 2000$

Engineering Research Bulletin, Vol 23,No 3, 2000 Minufiya University, Faculty of Engineering, Shebien El-Kom, Egypt, ISSN 1110-1180 
The SSR-phenomenon has been brought to great attention worldwide and in order to consolidate the studies in this area, the IEEE has patterned a special task force for SSR problem. The IEEE-SSR working group has published two Benchmark models in 1977 and 1985 for SSR simulations $[5,6,7]$ beside two reports, published at 1980 and 1985 , about the essential definitions and terms which may help in searching this phenomenon $[8,9]$. The two Benchmark models and the proposed definitions were broadly used by numerous research works in order to reduce the severity of SSR. Many SSRCountermeasure are proposed in many forms to increase the damping capability of the electric system [10-13]. These Countermeasures have been proposed in many forms, e.g. supplementary signals to the excitation system of the generator, tuned series and shunt filters, phase shifter, static var compensators and governors control arrangements. In four IEEE-SSR-Biographies, published at 1976, 1979, and 1991 respectively, holding more than 300 papers for SSR studies, it is found that in many of them the SSR-Countermeasures are only concerned with application of excitation system enhancement controllers for damping the SSR oscillations. Advanced control strategies such as fuzzy logic controllers and neural networks are also introduced to the power system stabilizers $[5,14]$. All the above controllers can be categorized as electrical SSR countermeasures. Such electrical countermeasures have proved some shortages especially due to the parameters uncertainties $[15,16]$.

In the contrary of all the above mentioned work, this paper presents a new trend which not only reduces the danger of the harmful oscillations, but also may, fundamentally, avoid the occurrence of this phenomenon. The trend is based on answering the question of the possibility to prevent the occurrence of SSR phenomenon through the early design of different turbo-generator shaft parameters.

\section{MODELLING OF POWER SYSTEM FOR SSR STUDY}

In the literature, there are plenty of models which are suggested to study SSR phenomenon. The previously mentioned two Benchmark models proposed by IEEE-SSR working group may be used to represent any power system having SSR problems. The EPN shown in $F i g(1)$ is suffering from this phenomenon. Accordingly, the Egyptian Electrical Authority (EEA) has appointed a team work to study and diagnose this phenomenon on it's network. The team work has approximated the part of the network, at which the phenomenon has takeu place to the IEEE First Benchmark model of Fig(2). This model consists of a $27^{\text {th }}$ order stiff non linear differential equations of which a full $8^{\text {th }}$ order equations for the gencrator where the damper windings are represented by one coil at the direct axis and two coils at quadrature axis $[5,6]$. The rest $19^{\text {th }}$ order equations include a $12^{\text {th }}$ order equation model to represent the mechanical mass-spring system of a three stage with reheat turbine-generator set, a $2^{\text {nd }}$ order model for the exciter and voltage regulator and a $5^{\text {th }}$ order model for the turbine governor system. This model can be expressed in the following standard state space form :

$\mathrm{A}(\mathrm{x}, \mathrm{t}) * \dot{\mathrm{X}}(\mathrm{t})=\mathrm{B}(\mathrm{x}, \mathrm{t}) * \mathrm{X}(\mathrm{t})+\mathrm{V}(\mathrm{t})+\Gamma^{*} \mathrm{Z}(\mathrm{t})$

Where;

$X(t)$ : is the system state vector having dimension of (27x1), and can be expressed as: 


$$
\begin{aligned}
& \mathrm{X}(\mathrm{t})=\mathrm{I}_{\mathrm{d}} \mathrm{i}_{\mathrm{f}} \mathrm{i}_{\mathrm{D}} \quad \mathrm{i}_{\mathrm{q}} \mathrm{i}_{\mathrm{Q} 1}{ }^{\mathrm{i}} \mathrm{Q} 2 \mathrm{v}_{\mathrm{cd}} \mathrm{v}_{\mathrm{cq}} \omega_{1} \omega_{2} \omega_{3} \quad \omega_{4} \omega_{5} \omega_{6} \delta_{1} \\
& \begin{array}{llllllllllllll}
\delta_{2} & \delta_{3} & \delta_{4} & \delta_{5} & \delta_{6} & \mathrm{~T}_{\mathrm{m} 1} & \mathrm{~T}_{\mathrm{m} 2} & \mathrm{~T}_{\mathrm{m} 3} & \mathrm{~g} & \mathrm{a} & \mathrm{V}_{\mathrm{R}} \mathrm{E}_{\mathrm{fd}} & \text { ] }
\end{array} \\
& \mathrm{V}(\mathrm{t})=\left[\begin{array}{lllll}
\sqrt{3} \mathrm{~V} \infty \sin (\delta) & 0 & 0 & \sqrt{3} \cos (\delta) \mathrm{V}_{\infty} & 0
\end{array}\right. \\
& \begin{array}{rrrrr}
0 & 0 & 0 & 0 & 0 \\
0 & 0 & 0 & 0 & -1 \\
-1 & -1 & -1 & -1 & -1 \\
0 & 0 & 0 & 0 & 0 \\
0 & 0 & ] & &
\end{array}
\end{aligned}
$$

Details of the matrices can be found in Reference [13] and the system parameters are given in appendix (1).

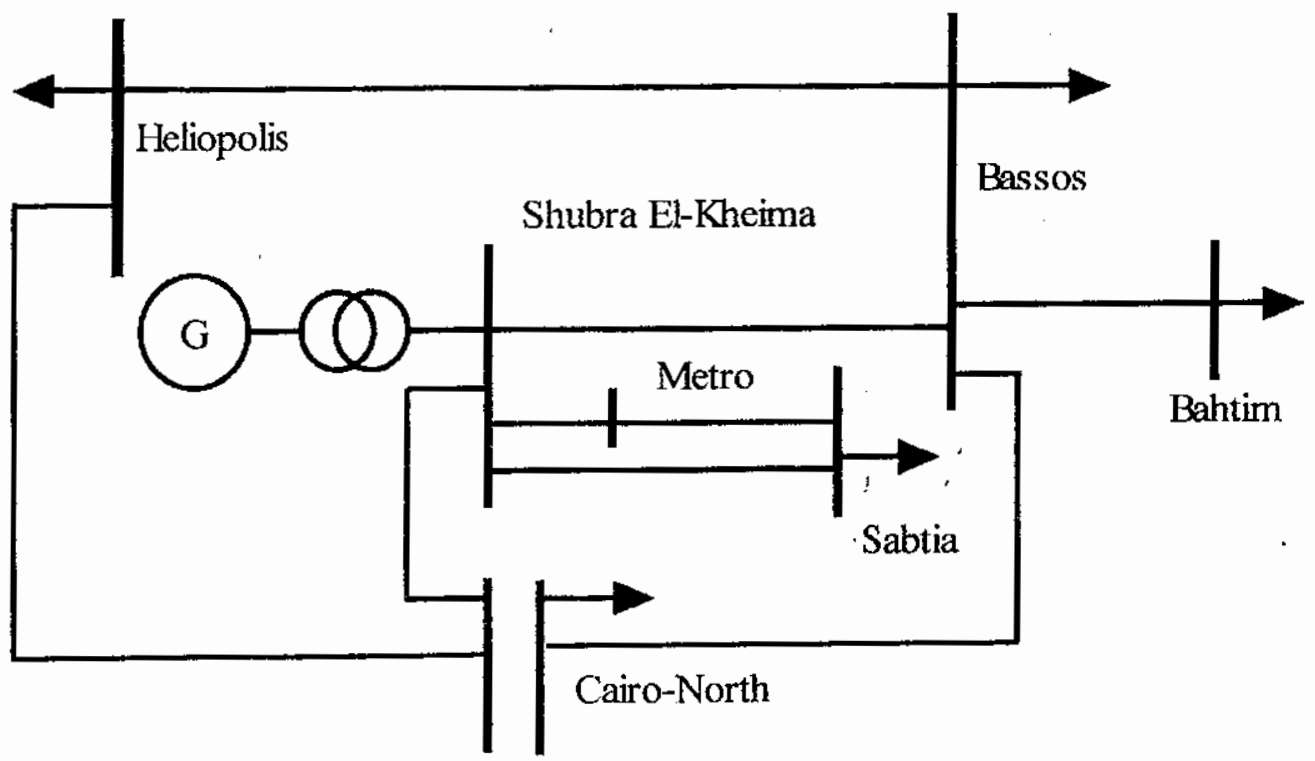

Fig(1) The Egyptian Network Used in The SSR Study.

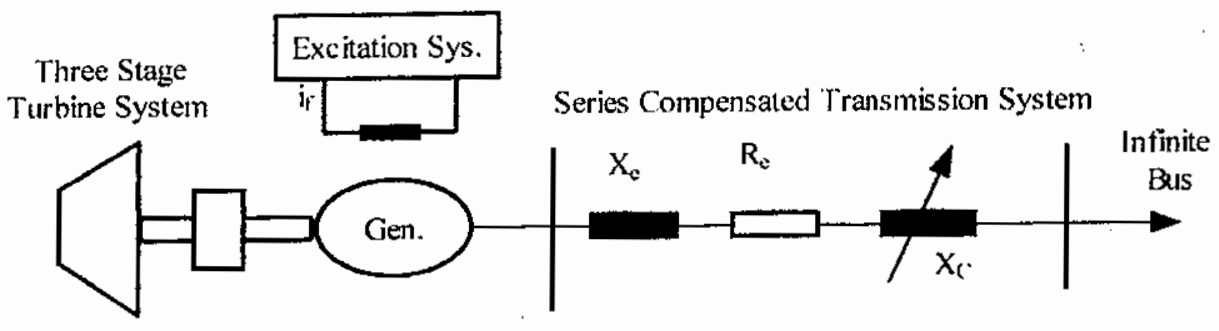

$\mathrm{m}_{\mathrm{n}} \quad \mathrm{m}_{\mathrm{et}}$

Hig (2) The IEEE Benchmark Model Which Represent The Part of

The Egyptian Network Exposed to SSR 


\section{PROPOSED SSR COUNTERMEASURE THROUGH MECHANICAL DESIGN}

The system parameters, specially those for the mechanical part are very important for the shaft oscillatory modes. This leads to the question if it is possible to prevent the occurrence of SSR problem through the early design of the different components constituting the power system design. This paper presents a new method for the design of the shaft parameters to reach reasonable parameters which avoids the danger of shaft failure.

The proposed workwill be organized as follows:

1- The effect of shaft parameters, i.e the spring constant between different masses (Kij), and the inertia constant of each mass(Hi) on the angular velocity $(\omega)$ (imaginary part of the eigenvalues) for the shaft modes will be shown in details for different values of Kij's and Hi's. This study will be performed on a wide range of these parameters. This will be an indication which oscillatory mode will be excited or damped.

2- The results of nonlinear time simulation will be given for the power system at these parameters and compared to the power system response for the nominal parameters of the Benchmark model.

3- The variation of real part of the eigenvalue with these parameters will be given to show which parameters will result in a stable modes. This will be again assured through the results of the nonlinear time simulation.

The above three-step procedures have been extensively performed overall the eleven parameters of the spring constants:K12, $\mathrm{K} 23, \mathrm{~K} 34, \mathrm{~K} 45$, \& $\mathrm{K} 56$, and the inertia constants: $\mathrm{H} 1, \mathrm{H} 2, \mathrm{H} 3, \mathrm{H} 4, \mathrm{H} 5$, \& $\mathrm{H} 6$.

To achieve the procedure objective of getting the optimum parameters which may result in desired performance, one have a plenty of results. Only those significant ones will be given here. For the first step, the proposed design strategy is performed such that Kij's and Hi's nearly been in the range of $\pm 20 \%$ more or less than the standard values given by the IEEE Benchmark model and the deviation of the torsional oscillations for the proposed shaft parameters from the steady state values will be calculated. The results of this design procedure will be explained as follows:

\subsection{Effect of spring constants:}

The results show that the system stability decreases with the increasment of K12 values. Fig(3-a) shows that the value of angular velocity $\omega$ increases for the modes 3,5 , but for the modes 1,2 the value of angular velocity $\omega$ did not change after $\mathrm{K} 12=12$. For the modes 0,4 , the change of $\mathrm{K} 12$ didn't have any effect. The nonlinear time simulation of the system with step change in electrical torque " Te " are shown in Fig(5). In this figure the torsional torque between different masses of the system are all increasing with the increase of $\mathrm{K} 12$ and decreasing with decrease of $\mathrm{K} 12$. Results of table (1) show the values of torsional torques between masses after a time of $(5 \mathrm{sec})$. 
Fig(3-b) shows the variation of real part of the eigenvalues with $\mathrm{K} 12$, from which one can find out the value of $\mathrm{K} 12$ that result in a stable mode (see table(7)).

For K34, Fig(3-c) shows that the values of $\omega$ increases with the increasment of $\mathrm{K} 34$ values for modes 1,4. Fig( 6 ) give the nonlinear time simulation of the system with the same fault as before. In this figure the torsional torque. between different masses of the system are all increasing with the increase of $\mathrm{K} 34$ and decreasing with decrease of K34. Also the torsional torques between masses after a duration of $(5 \mathrm{sec})$ can be found in table (2). The value of $\mathrm{K} 34$ that result in a stable mode can be clearly observed from the results of Fig(3-d). Later this value will be recommended for $\mathrm{K} 34$ as in table(7).

Fig(3-e) shows that $\omega$ increases with the increasment of K56 for all modes, except mode 5. For mode 5, when K56 reaches $10, \omega$ will increases with the increase of K56. In Fig(7), the torsional torque between different masses of the system are all decreasing with the increase of $K 56$ and increasing with decrease of $K 56$. The value of K56 that result in a stable mode can be found in table (7) which is based on the results given in both table (3) and the eigenvalues shown in Fig(3-f).

From the above results one can use the following observations as guide for selecting the different spring constants:

1. Referring to $\mathrm{Fig}(3-\mathrm{b})$, it is clear that large $\mathrm{K} 12$ values may lead to system instability as shown for mode 3 . Values of $\mathrm{K} 12$ which are more than double of the standard IEEE value will lead always to system instability. On the other side values of $\mathrm{K} 12$ which are less than 25 represent a tendency toward stability. Any value of $\mathrm{K} 12$ between 2 and 22 will give relatively stable modes. To ensure such results refer also to the change of torsional torques between different masses given in both table (1) and Fig(5).

2. Similar results of $\mathrm{K} 12$ show that smaller values of $\mathrm{K} 34$ will lead to system stability till a limit of $\mathrm{K} 34=32$ (Fig(3-d)). Afterward, modes 1, 4 will be unstable. Values of $\mathrm{K} 34$ which are more than the IEEE standard values lead always to unstable modes. This is also clear from the change of torsional torques between different masses given in both table (2) and Fig(6).

3. The system will be unstable for values of K56 more than 18 and remain unstable for all these values (Fig(3-f)). Stability can be guaranteed if K56 values are slected less than standard values. This is also obvious from the change of torsional torques between different masses given in both table (3) and Fig(7).

\subsection{Effect of inertia constants:}

For $\mathrm{H} 3$, Fig(4-a) shows that $\omega$ decreases with the increasment of $\mathrm{H} 3$. After $\mathrm{H} 2=0.4$, all modes did not change with the variation of H3. In Fig $(8)$ the torsional torque between different masses of the system are all increasing with the decrease of $\mathrm{H} 3$ and decreasing with the increase of $\mathrm{H} 3$. The results of table(4) show the values of torsional 
torques between masses after a duration of $(5 \mathrm{sec})$. From Fig(4-b) one can find out the value of $\mathrm{H} 3$ that result in a stable mode (table(7)).

Fig(4-c) shows that $\omega$ decreases with the increasment of $\mathrm{H} 4$ for mode 4 . The nonlinear time simulation of the system with step change in electrical torque " Te " are shown in Fig(9). In this figure the torsional torque between different masses of the system are all increasing with the increase of $\mathrm{H} 4$ and decreasing with decrease of $\mathrm{H} 4$. The results of table(5) show the values of torsional torques between masses after a duration of $(5 \mathrm{sec})$. Fig(4-d) shows the variation of real part of the eigenvalues with $\mathrm{H} 4$, from which one can find out the value of $\mathrm{H} 4$ that result in a stable mode (see table(7)).

Fig(4-e) shows that $\omega$ decreases with the increasment of $\mathrm{H} 5$ for mode 4 . The nonlinear time simulation of the system with step change in electrical torque " $\mathrm{Te}$ " are shown in Fig(10). In this figure the torsional torque between different masses of the system are all increasing with the decrease of $\mathrm{H} 5$ and decreasing with the increase of H5. The results of table(6) show the values of torsional torques between masses after a duration of $(5 \mathrm{sec})$. Fig(4-f) shows the variation of real part of the eigenvalues with H5, from which one can find out the value of H5 that result in a stable mode (see table(7)).

Similar observations showing the effect of changing the different inertias on the oscillatory modes can be summarized as follows:

1. From Fig(4-b), it is clear that selecting $\mathrm{H} 3 \leq 2.3$ will lead to system stability. Other values of $\mathrm{H} 3$ may lead to unstable modes of oscillation. [ Refer also to table (4), and Fig( 8 ) ].

2. The stability zone of $\mathrm{H} 4$ is a narrow one Fig(4-d). careful seof $\mathrm{H} 4$ should be in a small range around the IEEE standard values. This because values of $\mathrm{H} 4$ more or less IEEE standard values will lead to unstable modes (mode 1 , mode 3 ). This is also clear from both table (5) and Fig(9).

3. Referring to Fig(4-f), it is clear that large H5 values may lead to system stability. Values of H5 which are less than the IEEE standard values lead always to unstable modes (mode 1, mode 3, and mode 4). [Refer also to table(6), and Fig(10)].

An important step in the proposed design procedure is to check the above results through an extensive eigenvalue analyses of the model under study for the different proposed parameters. In summary, it is clear that the real parts of the eigenvalues for a selected parameters which give high oscillations tends to be positive and vice versa.

Finally, based on the above analysis, the best agreeable parameters for H's, and K's (which give no conflict with the practical consideration) are taken and a time simulation for this final model is performed. Fig(11) gives the results of this proposed model compared with those results for the IEEE Benchmark model. It is clear from these results that a proper design of the mechanical components of the power system may avoid completely the dangerous torsional oscillations which may happen if the system is exposed to faults which may excite SSR oscillations. 


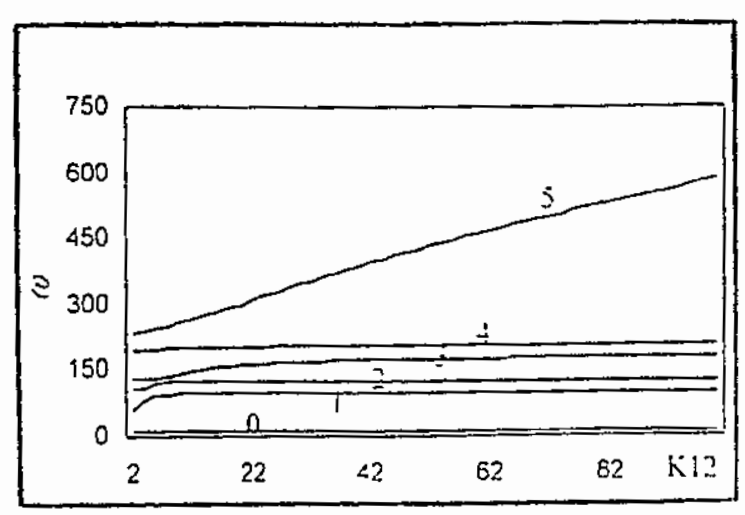

(a)

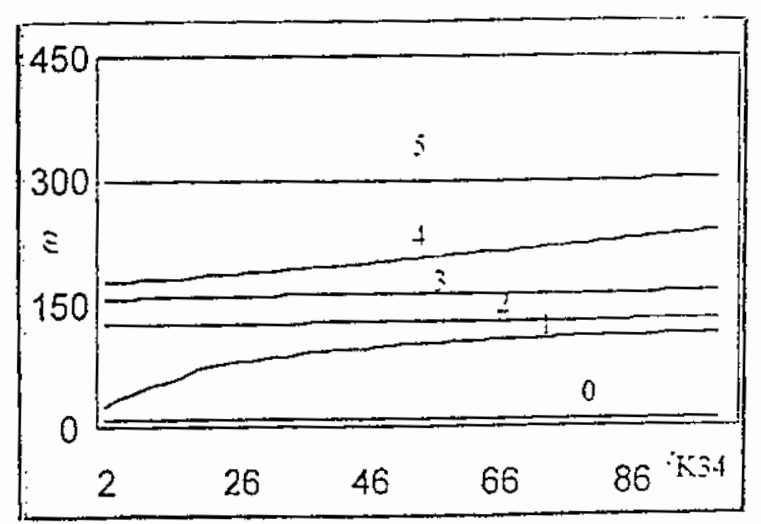

(c)

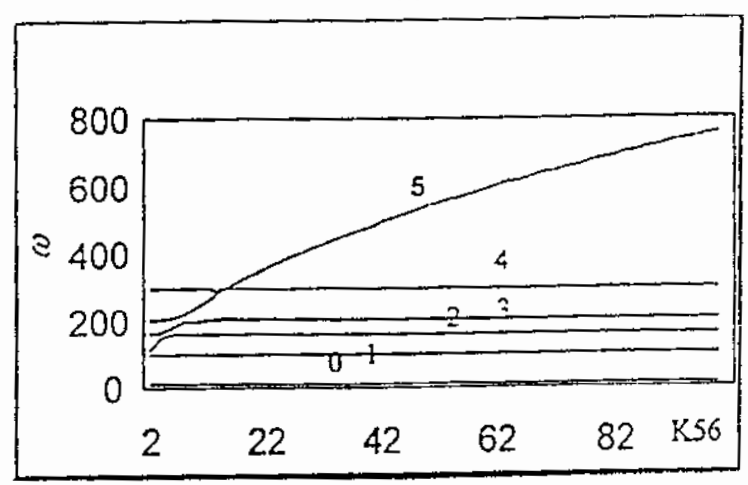

(e)

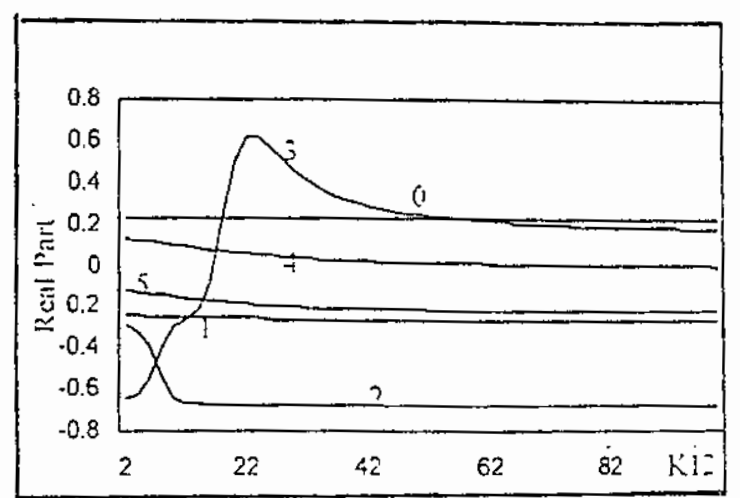

(b)

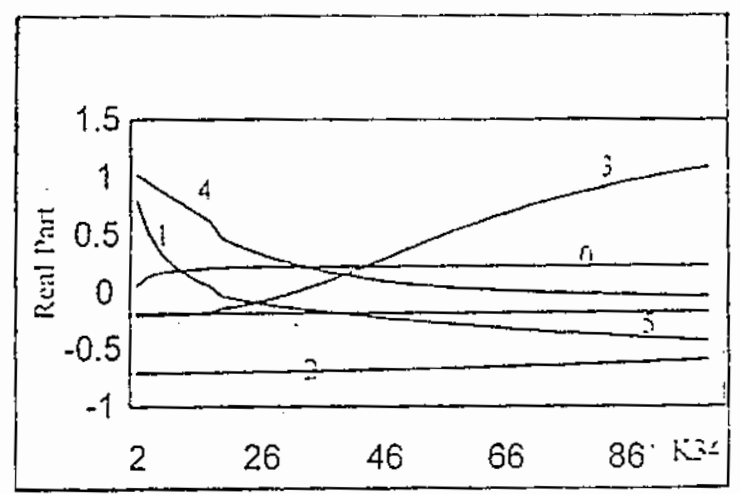

(d)

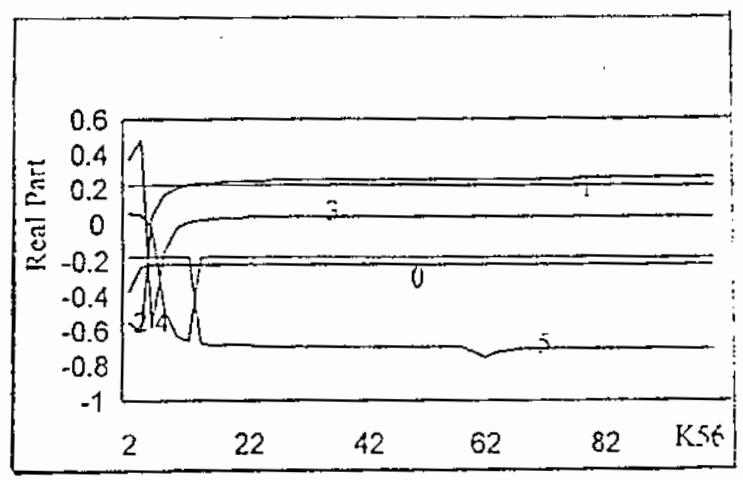

(ก)

Fig (3)Effect Of Spring Constants (K12,K34, And K56) On The Eigemalues 


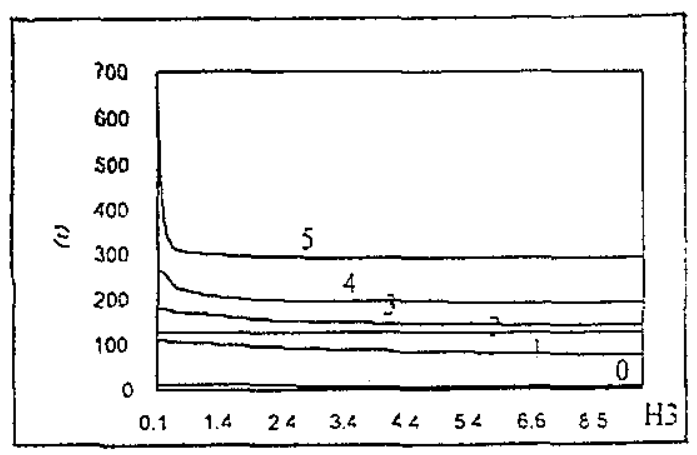

. (a)

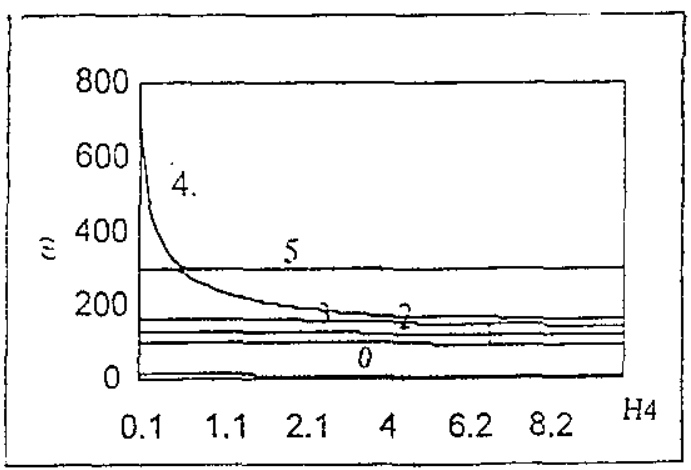

(c)

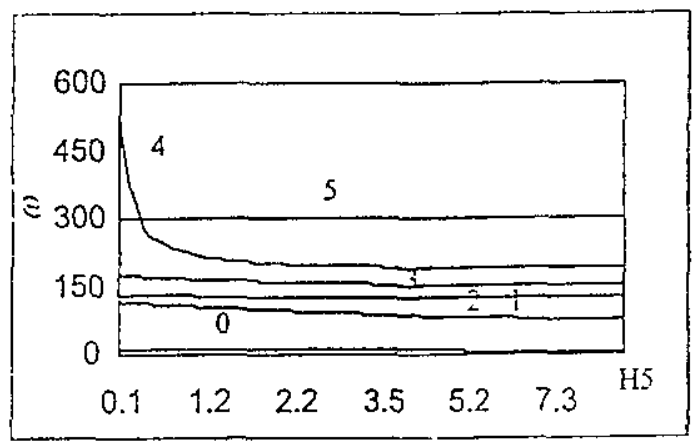

(e)

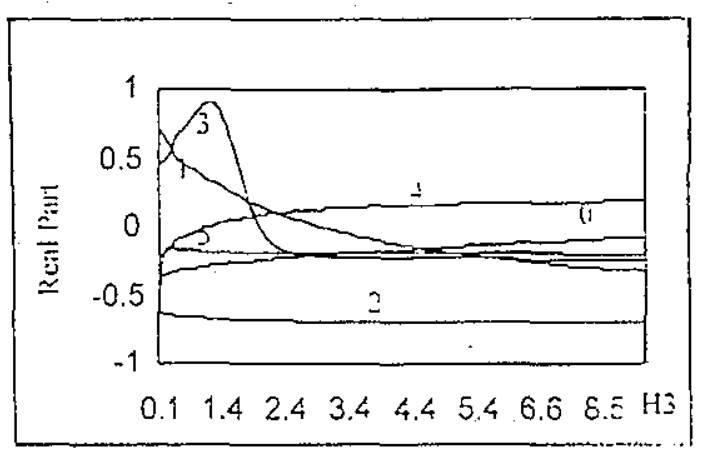

(b)

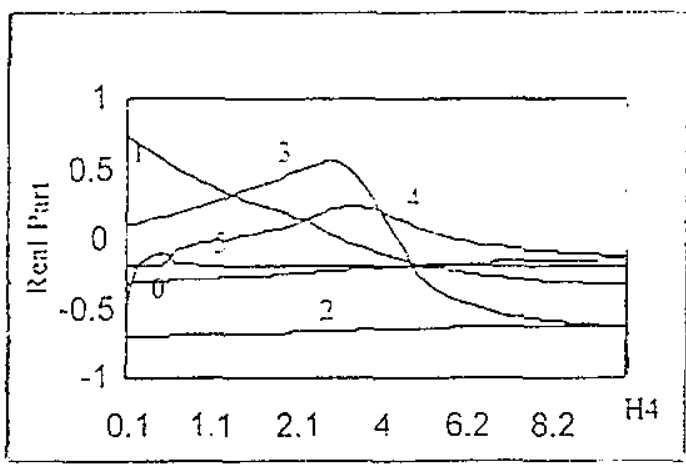

(d)

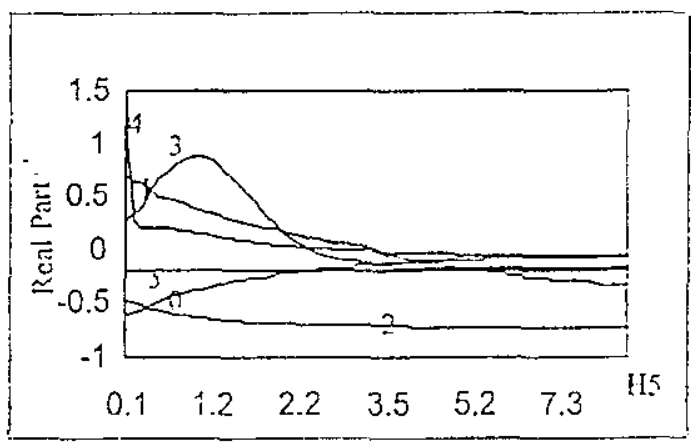

(f)

Fig (4) Effect Of Ineria Constants (H3,H4, And HS) On The Eigenvalues 

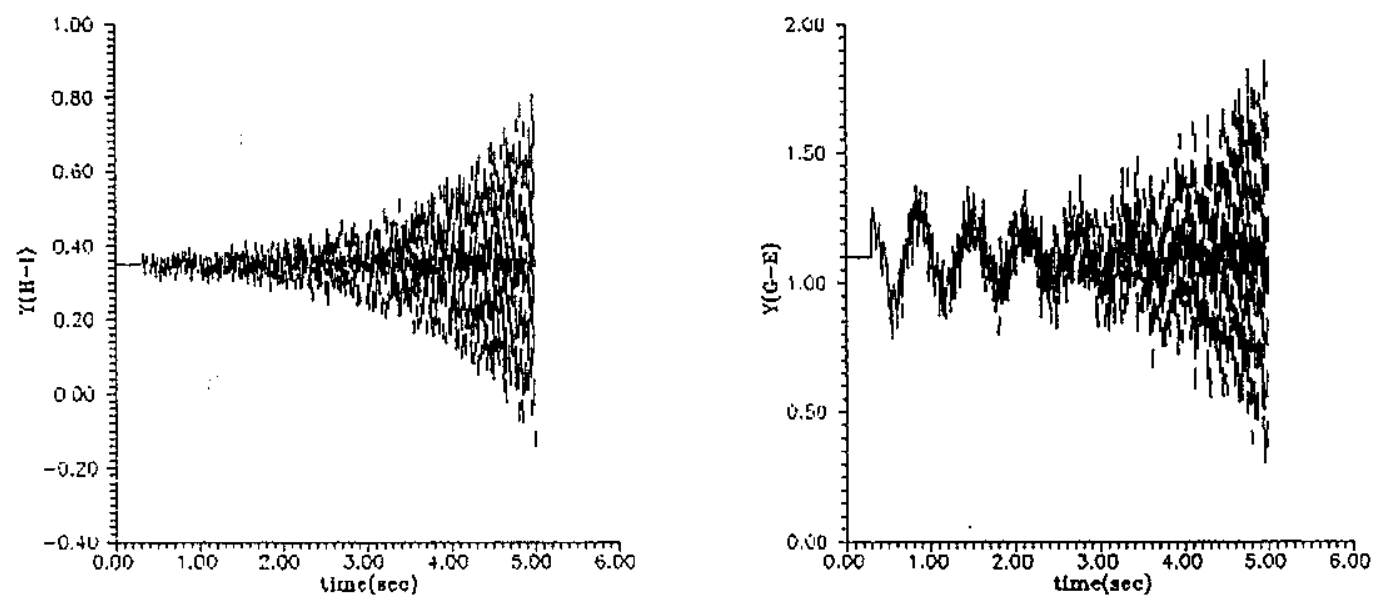

Fig (5) Eftict Of (K 12) On The Torsional Torques Btween Masses.

\begin{tabular}{|c|c|c|c|c|c|c|c|}
\hline \multirow{2}{*}{ torque } & \multirow{2}{*}{$\begin{array}{c}\mathrm{K} 12= \\
\text { (prefautt) }\end{array}$} & \multicolumn{2}{|c|}{$\begin{array}{l}19.3 \\
\text { IEEE }\end{array}$} & \multicolumn{2}{|c|}{$\begin{array}{l}25 \\
\sim\end{array}+20 \%$} & \multicolumn{2}{|c|}{$\begin{array}{c}14 \\
-\quad-20 \%\end{array}$} \\
\hline & & value & \%error & value & \%error & value & \%error \\
\hline$T(H-1)$ & 0.35 & 0.66 & $-89 \%$ & 0.8 & $-129 \%$ & 0.347093 & $1 \%$ \\
\hline$T(\mid-L)$ & 0.641 & 1.2 & $-87 \%$ & 1.5 & $-134 \%$ & 0.624325 & $3 \%$ \\
\hline$T(L-G)$ & 0.871 & 1.1 & $-26 \%$ & 1.13 & $-30 \%$ & 0.797672 & $: 8 \%$ \\
\hline $\mathrm{T}(\mathrm{G}-\mathrm{E})$ & 1.1 & 1.8 & $-64 \%$ & 1.95 & $.77 \%$ & 1.099402 & \& $.0 \%$ \\
\hline
\end{tabular}

Table (J) Effect Of The Spring Constant(K 12).
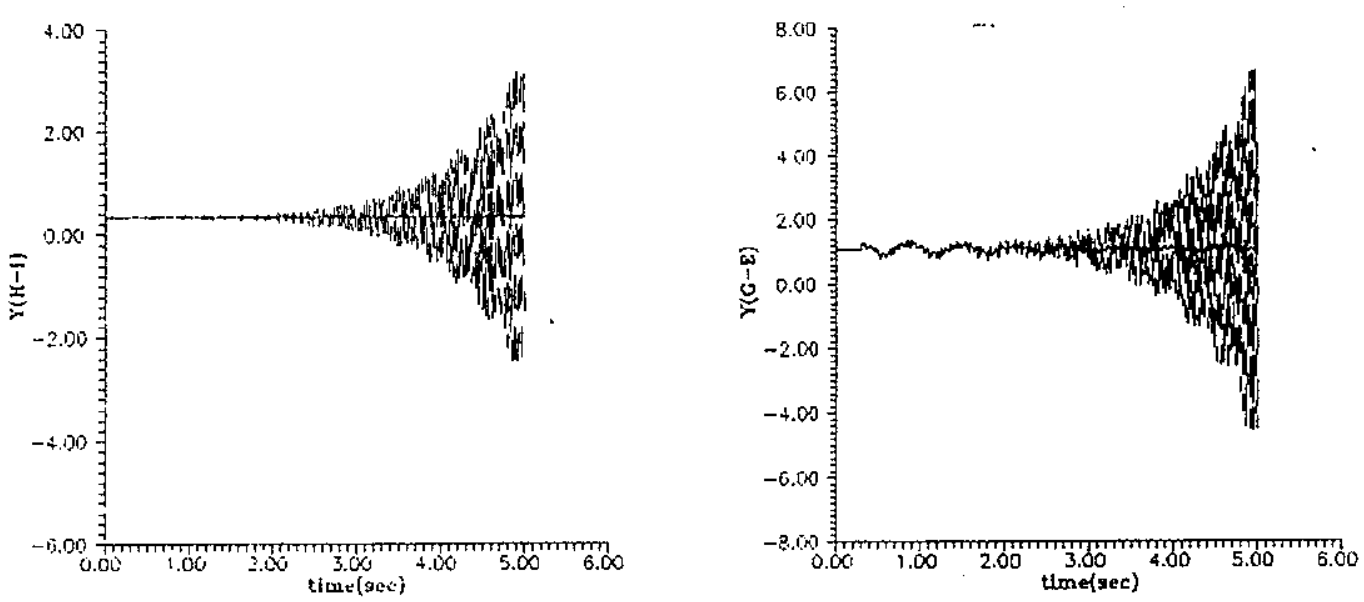

Fig (6) Ettect Of (K 34) On The Torsional Torques Btween Masses.

\begin{tabular}{|c|c|c|c|c|c|c|c|}
\hline \multirow{2}{*}{ torque } & \multirow{2}{*}{$\begin{array}{c}\begin{array}{c}\mathrm{K} 34= \\
\text { (prefault) }\end{array} \\
\text { Initial value } \\
\end{array}$} & \multicolumn{2}{|c|}{$\begin{array}{c}52.04 \\
\text { IEEE }\end{array}$} & \multicolumn{2}{|c|}{$\begin{array}{c}75 \\
\sim \quad+20 \%\end{array}$} & \multicolumn{2}{|c|}{$\begin{array}{l}36 \\
-\quad-20 \%\end{array}$} \\
\hline & & value & \%error & value & $\%$ error & value & \%error \\
\hline$T(\mathrm{H}-\mathrm{l})$ & 0.35 & 0.66 & $-89 \%$ & 4 & $-1043 \%$ & 0.352922 & $-1 \%$ \\
\hline$T(1 \cdot L)$ & 0.641 & 1.2 & $-87 \%$ & 6 & $.836 \%$ & 0.651278 & $-2 \%$ \\
\hline$T(L-G)$ & 0.871 & 1.1 & $-26 \%$ & 3.6 & $-313 \%$ & 0.940763 & $-8 \%$ \\
\hline$T(G-E)$ & 1.1 & 1.8 & $.64 \%$ & 7 & $-536 \%$ & 1.141983 & $-4 \%$ \\
\hline
\end{tabular}

Table (2) Effect Of The Spring Constant(K 34). 

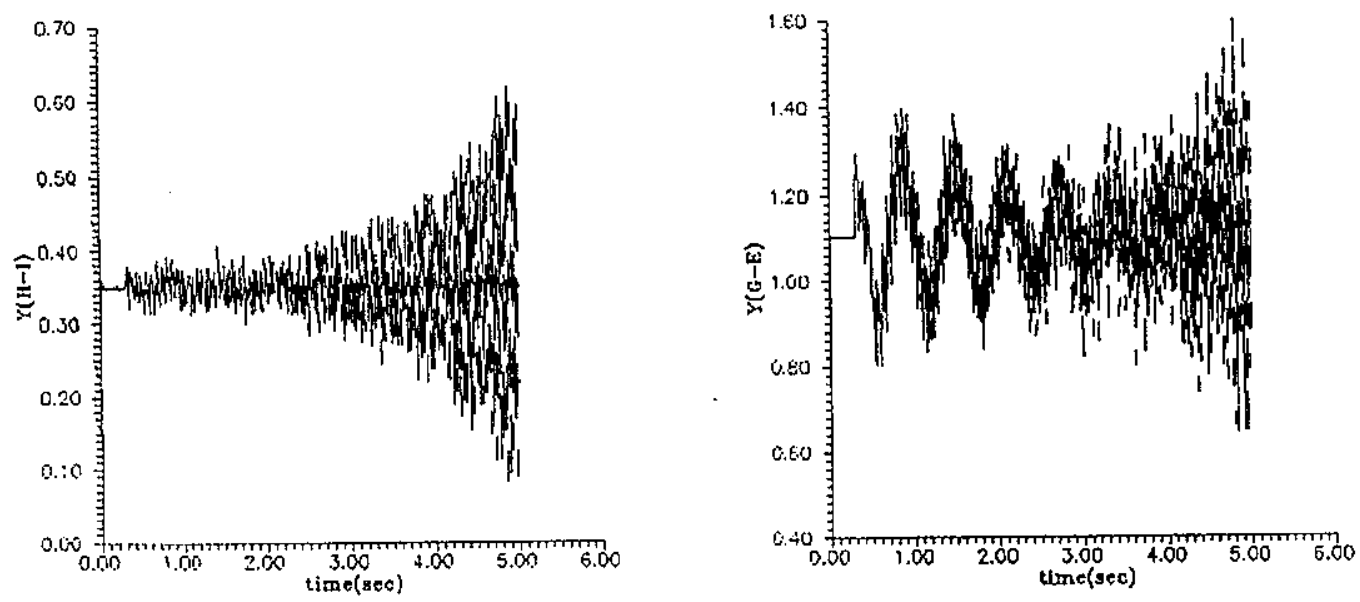

Fig (7) Ettixt Of (K 56) On The Torsional Torques Btween Mssjes.

\begin{tabular}{|c|c|c|c|c|c|c|c|}
\hline \multirow{3}{*}{ spring } & $\mathrm{K} 56=$ & \multirow{2}{*}{\multicolumn{2}{|c|}{$\begin{array}{l}2.82 \\
\text { IEEE } \\
\end{array}$}} & \multirow{2}{*}{\multicolumn{2}{|c|}{$\begin{array}{l}5.0 \\
+20 \% \\
\end{array}$}} & \multirow{2}{*}{\multicolumn{2}{|c|}{$\begin{aligned} & 0.8 \\
&-\quad-20 \% \\
&\end{aligned}$}} \\
\hline & (prefault) & & & & & & \\
\hline & Initial value & value & $\%$ error & value & $\%$ error & value & \%error \\
\hline$T(\mathrm{H}-\mathrm{-l})$ & 0.35 & 0.66 & $-89 \%$ & 0.365 & $-4 \%$ & 0.5 & $-44 \%$ \\
\hline$T(F-L)$ & 0.641 & 1.2 & $-87 \%$ & 0.66 & $-3 \%$ & 0.99 & $.55 \%$ \\
\hline$T(L-G)$ & 0.871 & 1.1 & $-26 \%$ & 0.95 & $-9 \%$ & 0.88 & $-1 \%$ \\
\hline$T(G-E)$ & 1.1 & 1.8 & $-64 \%$ & $t .15$ & $-5 \%$ & 1.25 & $-14 \%$ \\
\hline
\end{tabular}

Table (3) Effect Of The Spring Constant ( $K 56$ ).
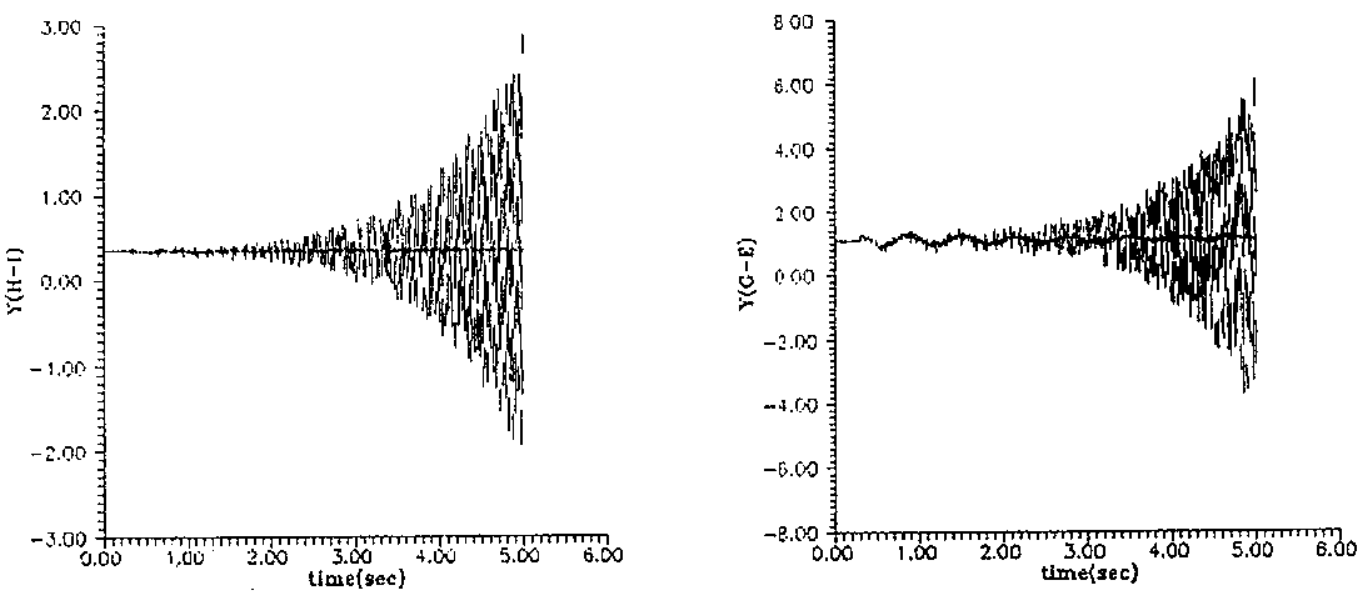

Fig (8) Ettect Of (H3) On The Torsional Torques Btween Masses.

\begin{tabular}{|c|c|c|c|c|c|c|c|}
\hline \multirow{2}{*}{ initia } & \multirow{2}{*}{$\begin{array}{c}\mathrm{H} 3= \\
\text { (prefault) }\end{array}$} & \multicolumn{2}{|c|}{$\begin{array}{r}1.7173 \\
\text { JEEE }\end{array}$} & \multicolumn{2}{|c|}{$\begin{array}{c}2.0 \\
-\quad+20 \%\end{array}$} & \multicolumn{2}{|c|}{$\begin{array}{r}0.717 \\
-\quad-20 \% \\
\end{array}$} \\
\hline & & value & \%error & value & \%error & value & \%error \\
\hline$T(\mathrm{H}-\mathrm{i})$ & 0.35 & 0.66 & $.89 \%$ & 0.37 & $-6 \%$ & 2.887043 & $-725 \%$ \\
\hline$T(1-L)$ & 0.641 & 1.2 & $-87 \%$ & 0.66 & $-3 \%$ & 4.433155 & $-592 \%$ \\
\hline$T(\mathrm{~L}-\mathrm{G})$ & 0.871 & 1.1 & $-26 \%$ & 0.93 & $-.7 \%$ & 1.4672 & $-68 \%$ \\
\hline & 11 & 1.8 & $.64 \%$ & 1.15 & $.5 \%$ & 2.658562 & $-142 \%$ \\
\hline
\end{tabular}

Table (4) Etfect (ot The Inertia Constant ( $\mathrm{H} 3$ ). 

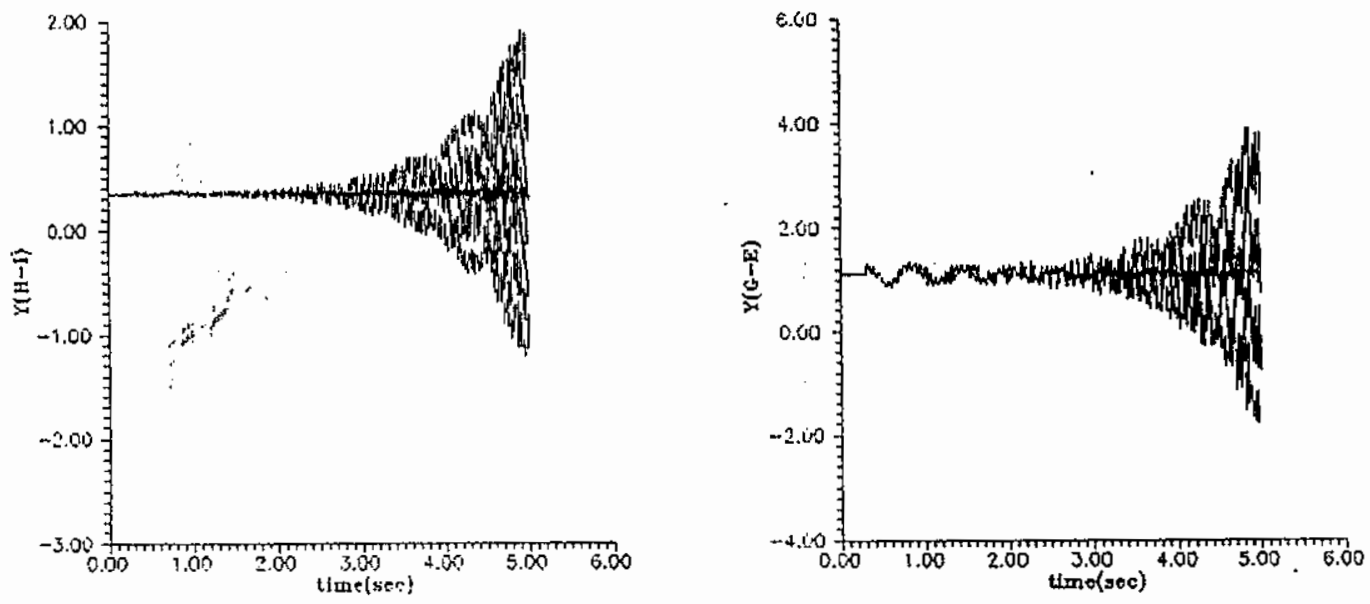

Fig (9) Elfict Of (H4) On The Torsional Torques Btween Masses.

\begin{tabular}{|c|c|c|c|c|c|c|c|}
\hline \multirow{3}{*}{ torque } & \multirow{3}{*}{$\begin{array}{c}\mathrm{H}_{4}= \\
\text { (prefault) } \\
\text { Initial value }\end{array}$} & \multirow{2}{*}{\multicolumn{2}{|c|}{$\begin{array}{c}1.7684 \\
\text { JEEE }\end{array}$}} & \multirow{2}{*}{\multicolumn{2}{|c|}{$\begin{array}{r}2.4 \\
-\quad+20 \% \\
\end{array}$}} & \multicolumn{2}{|c|}{.768} \\
\hline & & & & & & $\sim$ & \\
\hline & & value & \%error & vatue & \%error & value & \%error \\
\hline$T(H-1)$ & 0.35 & 0.66 & $-89 \%$ & 2 & $.471 \%$ & 0.294119 & $16 \%$ \\
\hline$T(I-L)$ & 0.641 & 1.2 & $-87 \%$ & 3.5 & $-446 \%$ & 0.552673 & $14 \%$ \\
\hline$T(L-G)$ & 0.871 & 1.1 & $-26 \%$ & 1.75 & $-101 \%$ & 0.933744 & $-7 \%$ \\
\hline$T(G-E)$ & 1.1 & 1.8 & $-64 \%$ & 4.4 & $.300 \%$ & 1.218445 & $-11 \%$ \\
\hline
\end{tabular}

Table (5) Effect Of The Inertia Constant ( $\mathrm{H} 4)$.
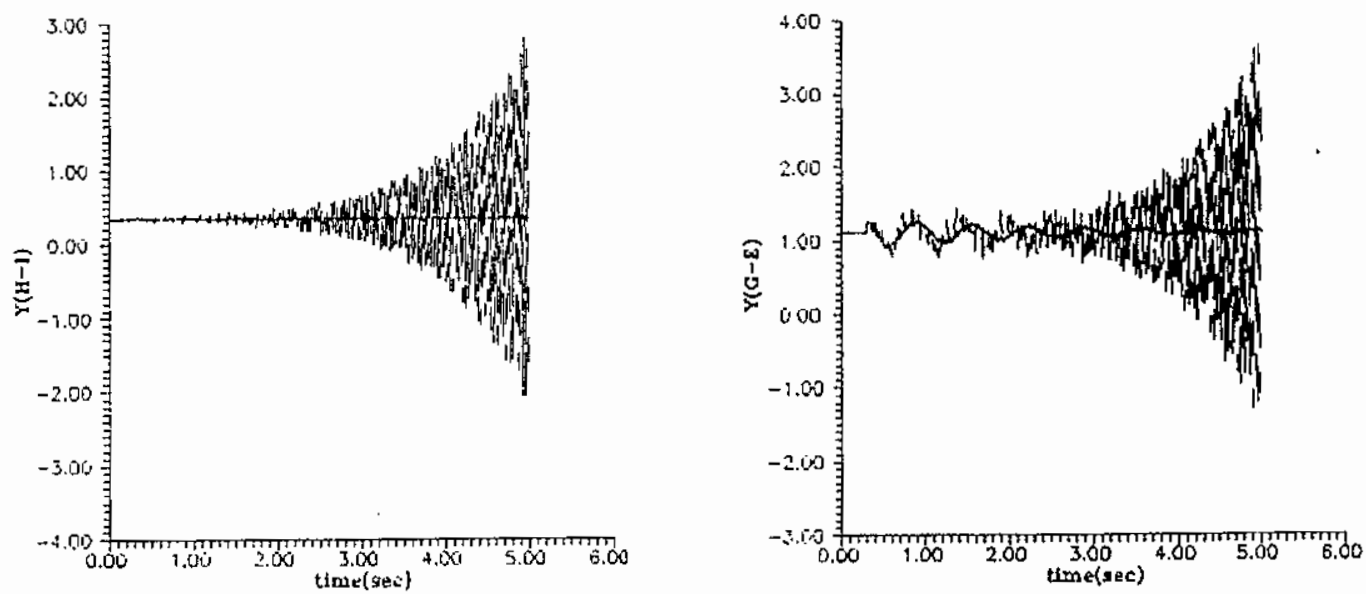

Fig (10) Effect Of (H5) On The Torsional Torques Btween Masses.

\begin{tabular}{|c|c|c|c|c|c|c|c|}
\hline \multirow{2}{*}{ torque } & \multirow{2}{*}{$\begin{array}{c}\mathrm{H} 5= \\
\text { (prefault) }\end{array}$} & \multicolumn{2}{|c|}{$\begin{array}{l}1.74 \\
\text { IEEE }\end{array}$} & \multicolumn{2}{|c|}{$\begin{array}{r}2.5 \\
-\quad+20 \% \\
\end{array}$} & \multicolumn{2}{|c|}{$\begin{array}{l}.735 \\
\sim-20 \% \\
\end{array}$} \\
\hline & & value & \%error & value & \%error & value & \%erro \\
\hline$T(\mathrm{H}-\mathrm{I})$ & 0.35 & 0.66 & -0.88571429 & 0.357 & -0.02 & 2.815972 & $-705 \%$ \\
\hline$T(I-L)$ & 0.641 & 1.2 & -0.87207488 & 0.654 & $-0,02028081$ & 4.08013 & $.537 \%$ \\
\hline$T(L \cdot G)$ & 0.871 & 1.1 & -0.26291619 & 0.92 & -0.05625718 & 2.073565 & $-138 \%$ \\
\hline & 1.1 & 1.8 & -0.63636364 & 1.14 & -0.03636364 & 2.797455 & $-154 \%$ \\
\hline
\end{tabular}

Tisble (6) Effect Of The Inertia Constant (HS). 

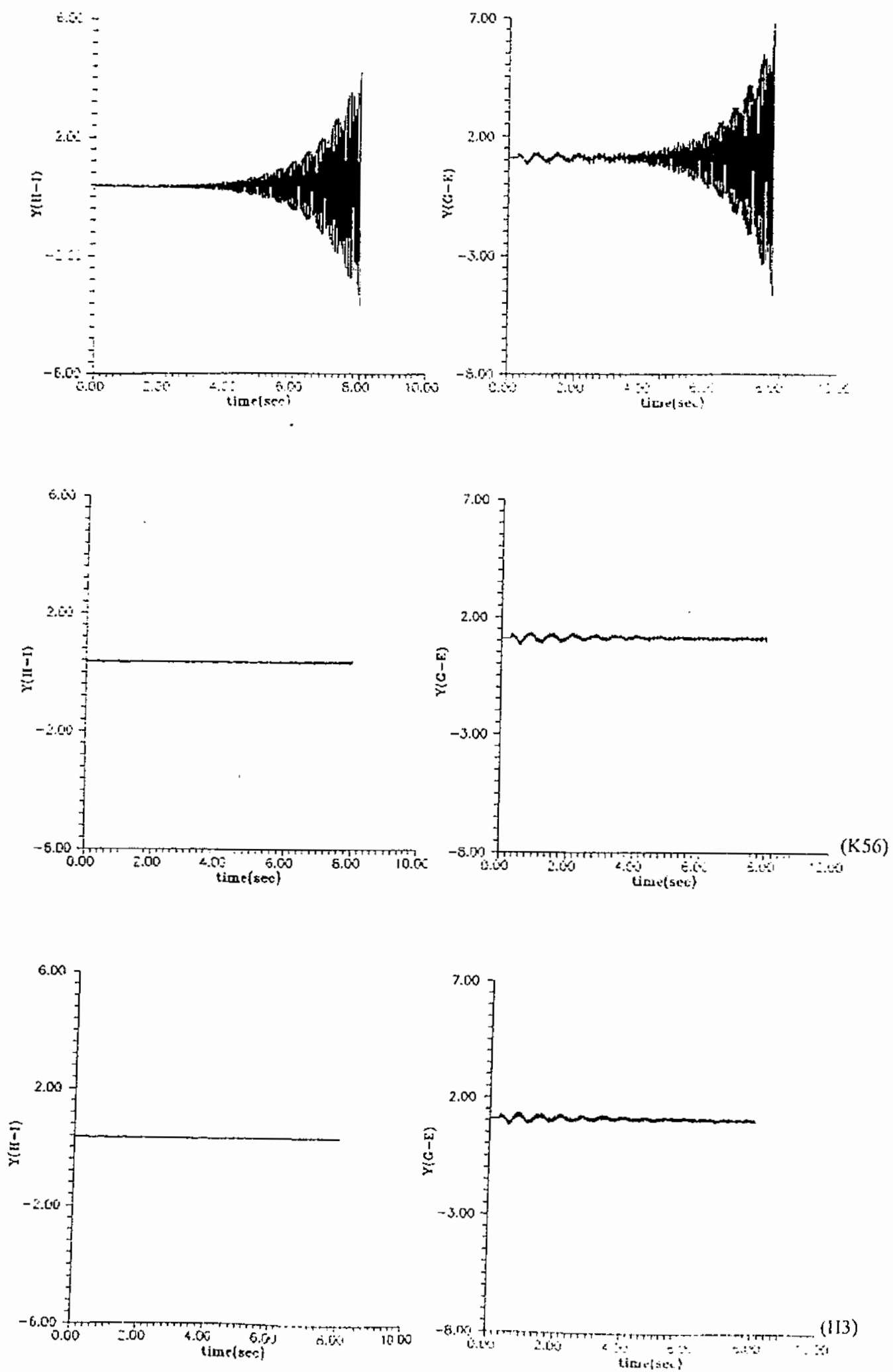

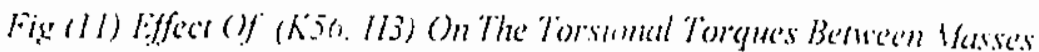


Table(7) give a recommended parameters for a power system having the same ratings as given by the IEEE Benchmark model may be in these ranges to avoid or reduce the effects of SSR problems.

\begin{tabular}{|c|c|c|c|c|c|}
\hline $\begin{array}{c}\text { Inertia } \\
\text { Const. } \\
(\mathrm{Hi})\end{array}$ & IEEE value & Suggested values & $\begin{array}{c}\text { Spring const. } \\
(\mathrm{Kij})\end{array}$ & IEEE value & $\begin{array}{c}\text { Suggested } \\
\text { values }\end{array}$ \\
\hline $\mathrm{H} 1$ & 0.1858 & $\approx 0.15$ & $\mathrm{~K} 12$ & 19.3 & $2.0-22.0$ \\
\hline $\mathrm{H} 2$ & 0.3112 & $1.3-2.5$ & $\mathrm{~K} 23$ & 34.929 & $2.0-32.0$ \\
\hline $\mathrm{H} 3$ & 1.7173 & $1.3-3.1$ & $\mathrm{~K} 34$ & 52.04 & $35.0-55.0$ \\
\hline $\mathrm{H} 4$ & 1.7684 & $\approx 2.3$ & $\mathrm{~K} 45$ & 70.9 & $14.0-50$ \\
\hline $\mathrm{H} 5$ & 1.74 & $0.8-1.8$ & $\mathrm{~K} 56$ & 2.82 & $2.0-12.0$ \\
\hline $\mathrm{H} 6$ & 0.0684 & $\approx 1.1$ & & & \\
\hline
\end{tabular}

Table(7) Recommended Values For The Different Shaft Parameters

\section{CONCLUSION}

Many SSR countermeasures are presented in the literature. Only few of them are concerned with mechanical countermeasures. This is mainly because the ordering and manufacture of the turbine-generator has often been done long before the SSR problem happened. This paper has presented a new method toward avoiding this phenomenon by suggesting an appropriate design of the shaft parameters. Such a new trend not only reduces the danger of the harmful oscillations, but also may, avoid the occurrence of this phenomenon or at least minimize the shaft torsional oscillations. Results of this paper has led to agreeable values for the shaft parameters, which can be used safely to get an acceptable shaft ctorsional oscillations.

\section{LIST OF SYMBOLS}

\section{General}

$\mathrm{A}, \mathrm{B} \quad$ :system matrices

$\delta, \omega \quad$ :Machine angle and speed

$\mathrm{R}, \mathrm{L} \quad$ :Resistance and inductance

T :Torque

a :Actuator signal

g :Governor opening

$\mathrm{M}(2 \mathrm{H}) \quad$ :Moment of inertia

I :Currents

$\mathrm{V} \quad$ :Voltage

\section{Subscripts:}

$\mathrm{d}, \mathrm{q} \quad \mathrm{d}$-axis and $\mathrm{q}$-axis quantities

F :Field circuit

D $\quad$ :D-axis damper 


$\begin{array}{ll}\text { Q1,Q2 } & \text { :Q-axis damper } \\ \mathrm{C} & \text { :Series capacitor } \\ \mathrm{T} & \text { :Generator terminal } \\ \mathrm{N} & \text { :Infinite bus quantity } \\ \mathrm{HP} & \text { :High pressure turbine-section } \\ \mathrm{IP} & \text { :Intermediate pressure turbine-section } \\ \mathrm{LPA}, \mathrm{LPB} & \text { :Low pressure turbine -section } \\ \mathrm{E} & \text { :Electrical } \\ \mathrm{m} & \text { :Mechanical } \\ \mathrm{B} & \text { :Susceptance }\end{array}$

\section{APPENDIX}

System data:

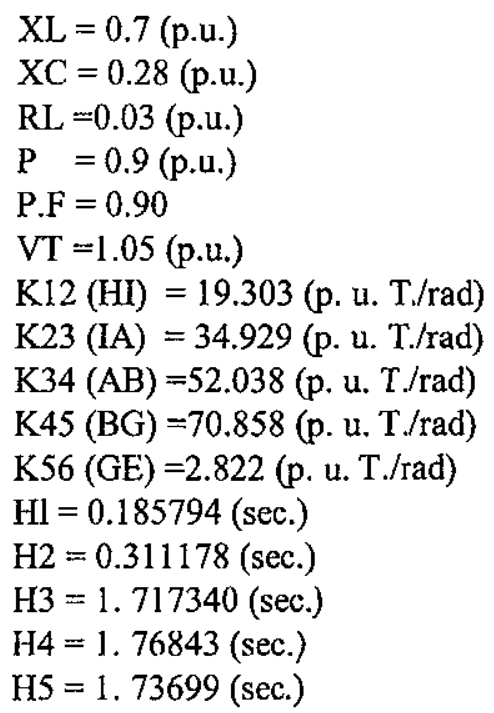

$$
\begin{aligned}
& \mathrm{H} 6=0.068433 \text { (sec.) } \\
& M Q=1.58 \text { (p.u.) } \\
& L D=1.79 \text { (p.u.) } \\
& \mathrm{LQ}=1.71 \text { (p.u.) } \\
& \mathrm{R}=0.0015 \text { (p.u.) } \\
& \mathrm{F} 1=0.3 \\
& \mathrm{~F} 2=0.26 \\
& \mathrm{~F} 3=0.22 \\
& \mathrm{~F} 4=0.22 \\
& \mathrm{LQ1}=1.695 \text { (p.u.) } \\
& \mathrm{LQ} 2=1.825 \text { (p.u.) } \\
& \mathrm{LF}=1.7 \text { (p.u.) } \\
& \mathrm{LDD}=1.666 \text { (p.u.) } \\
& \mathrm{D} 1=0.1 \text { (p.u. sec.) } \\
& \mathrm{D} 2=0.1 \text { (p.u. sec.) }
\end{aligned}
$$

\section{REFERENCES}

1. M. C. Hall and D. A. Hodges, "Experience with $500 \mathrm{KV}$ subsynchronous resonance and resulting turbine generator shaft damage at Mohave generation station" IEEE SSR task force as special publication. No. 76 CH1066-PWR. PP 22-29, IEEE Newyork, 1976.

2. G. R. Farmer, E. Katz and A. L. Schwalb, "Navajo project report on SSR analysis and solution" IEEE PAS, Vol. PAS-96, NO. 1, July/august 1977 P. P. 1226-1232.

3. IEEE SSR Working Group, "Proposed term and definitions for subsynchronous resonance" IEEE Symposium on Countermeasures for Subsynchronous Resonance. IEEE Pub. 81TH0086-9-PWR .1981, p 92-97. 
4. Egyptian Electricity Authority (EEA), "Impact of system disturbances on torsional oscillations of shoubra al-kheima generating units" March, 1994, Cairo, Egypt.

5. A. M. Abdel-Hamid, H. A Nour Eldin, "Modeling and analysis of SSR turbine-shaft oscillations in power systems incorporating superconducting generators." IEEE Nableul- Hammamet, Tunisia, April 1-4, 1998.

6. IEEE Task Force on SSR, "First Benchmark model for computer simulation of subsynchronous resonance "IEEE PAS, Vol. PAS-96, No. 5, P. P. 15651572 Sept ./oct. 1977.

7. IEEE Task Force on SSR, "Second Benchmark model for computer simulation of subsynchronous resonance "IEEE PAS , Vol . PAS-104, NO .5, P.P. 1057-1066, May, 1985 .

8. IEEE Subsynchronous Resonance Working Group, "Proposed term and definitions for subsynchronous oscillations" IEEE Trans. on PAS, Vol-PAS-99, No.2, March/Apr. 1980.

9. IEEE Subsynchronous Resonance Working Group, "Term definitions and symbols for subsynchronous oscillations" IEEE Trans on PAS, Vol. PAS-104, No. 6, June 1985.

10.Andrew Yan, Yao-Nan YU, "Multi-mode stabilization of torsional oscillations using output feedback excitation control" IEEE Transactions on power apparatus and system, Vol. PAS-101, No. 5, May 1982.

11.A. M. Abdel Hamid, H. J. Nern, A. A. EL Hefnawy and H. A. Nour Eldin, "Simulation for torsional oscillations and subsynchronous resonance (SSR) dynamics in larg power system generators" IMAC-IFAC international symposium on mathematical and intellegent models in system simulation. Belgium, p. p. VI. C. 5-1 : 5-8, September, 3-7, 1990.

12.A.M.Abdel Hamid, S.Osheba, A.A. Hefnawy and H.A.Nour Eldin, "Realtime stabilizing signal generation subsynchronous resonance trough nonlinear synchronous generator observer" IFAC-Greece, 1991.

13.A.M.Abdel Hamid, "Combined static VAR and voltage control system" ph.D.These, EL- Menoufia Univ., Nov.1991.

14.A. M. Abdel-Hamid, "A novel approach to improve the performance of FuzzyLogic based controllers for systems with wide range disturbance and uncertain parameters", Engineering Research Bulltin, Menoufia university, Fac. of Eng., Shebin El-kom, Vol, 22, No. 3, P. P. 41-56, 1999.

15.A. M. Abdel-Hamid, "A model analysis based load frequency-control considering parameter uncertainties and generation tare constraints", 42. Internationales Wissenschaftliches Kolloqium (Informatik und Automatisierung im Zeitalter der Informationsgesellschaft), Faculty of information and control, university of Ilmenau, Germany, Vol.3, pp.705-710, 22-25 sept. 1997.

16.S. - K shen, T. - T. lee, and B. - C. Wang, "Frequency domain design method for uncertain systems under some unknown-but-bounded disturbances", Iee Proc. control theory Appl., vol. 144, No. 3, May, 1997. 
291

भुरां

6.

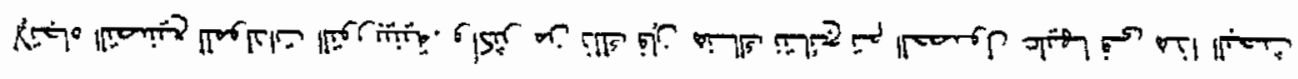

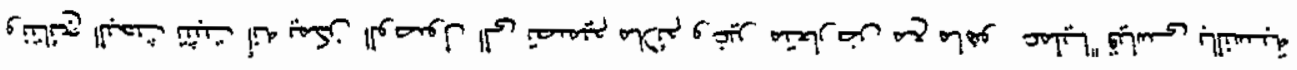

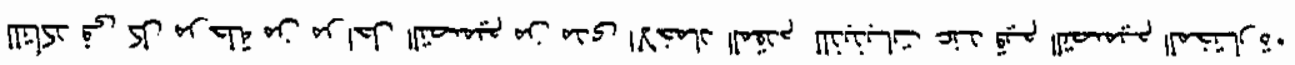

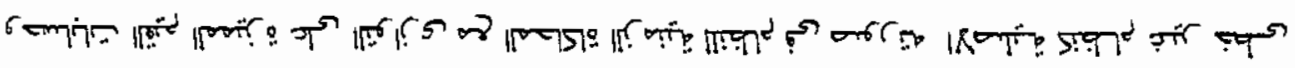

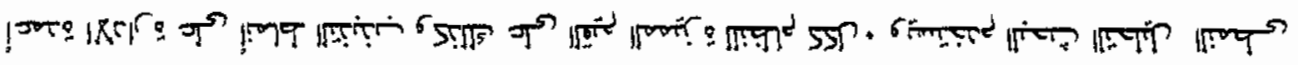

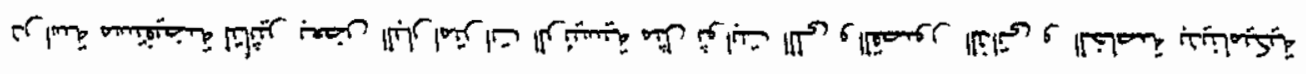
काष

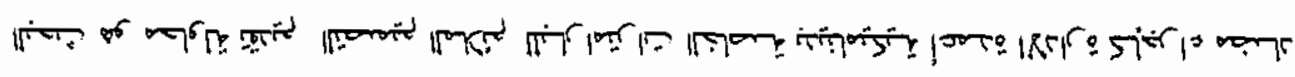

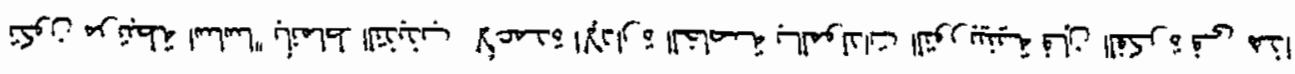

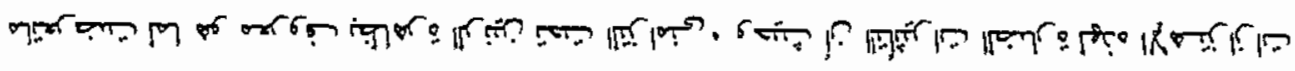

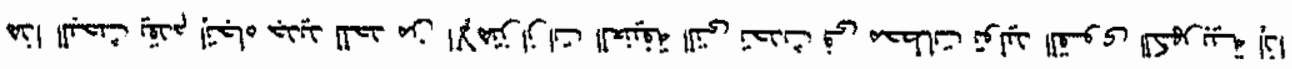

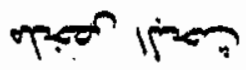

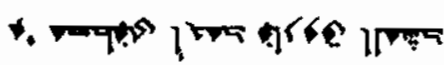

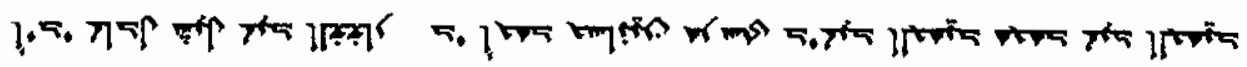

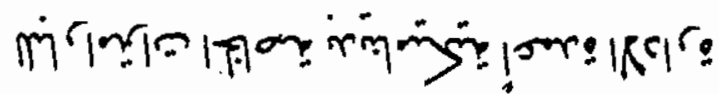

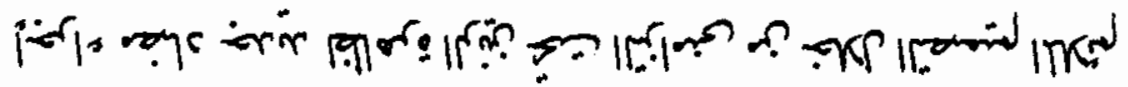

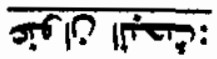

